A fines del año 1999, durante el invierno del hemisferio norte, la actividad de la influenza apareció más temprano que otros años ya que se adelantó entre 7 y 8 semanas con respecto al período 1988-1999. En algunas regiones de Europa y EE.UU. esta comenzó a incrementarse progresivamente llegando a presentar un número de casos que excedió varias veces los niveles esperados. Esta importante morbilidad constituyó un problema de salud de tal magnitud que durante algunas semanas tuvo en vilo a los sistemas de vigilancia y a las organizaciones nacionales de salud pública. En distintos países, los reportes de los médicos centinelas del número de visitas por "cuadros tipo influenza" (Influenza like illness (ILI)) cada 1000 visitas-paciente aumentaron en tal proporción que definieron desde niveles de brotes regionales hasta brotes diseminados. Incluso la mortalidad atribuída a influenza y neumonía reportada por el sistema de monitoreo en EE.UU. se incrementó, según la semana reportada, entre un 20 y un $30 \%$ por encima del umbral epidémico.

Con respecto al tipo de virus responsable, se han identificado en algo más del $99 \%$ de los casos al tipo A, subtipo H3N2. En los tres últimos años, el tipo predominante en los EE.UU. ha sido el A/Sidney/05/97, uno de los tipos identificados en nuestro país durante el período enero - junio de1999 $y$, por lo tanto, recomendado como un componente de la vacuna.

En España, Suiza, Dinamarca, y otros lugares de Europa, los subtipos de A/H3N2 identificados fueron el Sidney y el Moscow.

En el hemisferio sur, el pico de actividad gripal se espera desde abril y se extiende hasta septiembre. Atento al impacto que la epidemia en Europa y EE.UU. pueda tener en nuestro medio creemos que es útil ofrecer esta guía de maniejo.

\section{Vacuna antigripal:}

Dado que hasta ahora no se ha logrado producir una vacuna basada en el tipo A/Moscow/10/99, la recomendación de la OMS para el hemisferio sur es distribuir una vacuna con un componente predominante de A/Sidney/05/97 ya que esta relacionada antigénicamente al tipo Moscow, aún cuando la eficacia de este tipo de cobertura cruzada no se puede anticipar. La vacuna es a virus muertos, partes o enteros (polivalente para las cepas esperadas cada año) y su eficacia, si bien depende de la coincidencia de las cepas utilizadas con las presentes en la comunidad, varía entre el 70 y el $90 \%$, siendo mayor en los jóvenes, menor en los ancianos y en pacientes con enfermedades crónicas.

Posología: una dosis anual IM en el deltoides o en cara anterolateral del muslo en los niños pequeños. Brinda protección luego de 1-2 semanas y cae con el correr de los meses por lo que no debe anticiparse ni retrasarse demasiado de marzo-abril para poder cubrir el pico la estación gripal que en el hemisferio sur va de abril a septiembre.

Efectos adversos: reacciones alérgicas en pacientes con marcada alergia al huevo. Menos de un tercio refieren sensibilidad en el sitio de punción y 5-10\% fiebre leve durante el $1^{\text {er }}$ día de vacunado (es más común en niños nunca expuestos a la gripe).

Contraindicaciones: Alergia al huevo. Enfermedades triviales como las de vía aérea superior no son una contraindicación. Tampoco lo son el embarazo ni el amamantamiento.

Los grupos con mayor morbi-mortalidad por Gripe o participantes importantes de la cadena epidemiológica deben recibir la vacuna (ver tabla)

\section{Grupos de riesgo (indicación clara)}

- Personas $\geq a$ años

- Pacientes con enfermedades metabólicas (incluida diabetes), hemoglobinopatías, inmunosupresión (incluído HIV y corticoterapia $20 \mathrm{mg}$ por más de 2 a 4 semanas) o insuficiencia renal.

- Personal de salud, de instituciones de $3^{\text {er }}$ nivel o convivientes en contacto con este grupo de pacientes.

- Niños y adolescentes (de 6 meses a 18 años) en tratamiento crónico con aspirina (por el riesgo de Sme. De Reye).

\section{Se deberá considerar en:}

- Internados en $3^{\text {er }}$ nivel

- Trabajadores comunitarios

- Embarazadas en 2do y 3er trimestre ( $\geq 14$ semanas de gestación) durante la estación gripal (se previenen 1-2 internaciones cada 1000 vacunadas). Si la embarazada tiene factores de riesgo debe vacunarse en Marzo-Abril independientemente de la edad gestacional.

Muchas personas con indicación de inmunización no se vacunan debido a errores de concepto sobre la gripe y la vacuna antigripal. Hay quien percibe a la gripe simplemente como una molestia y a la vacuna como causa de frecuentes efectos adversos. Los vacunados entre los años '40-'60 quizás recuerden muchos más efectos adversos que lo que actualmente sucede con la vacuna más purificada. Hay quien piensa que la vacuna puede reproducir la gripe pero esto es imposible pues la vacuna actualmente utilizada es a virus muertos. Algunas personas no reciben la vacuna pues no la consideran efectiva. En muchos casos esto se debe a que luego de inmunizrse tienen un cuadro viral confundido con gripe cuando en realidad la vacuna antigripal, no protege contra los cuadros virales típicos del invierno. En otros casos ocurre que efectivamente se tuvo gripe a pesar de la inmunización, esperando una eficacia del $100 \%$ que la vacuna no tiene (las cepas vacunales se preparan 9-10 meses antes de la estación gripaly los virus mutan en mayor o menor medida durante ese tiempo).

\section{Eficacia:}

Aún cuando las mutaciones reduzcan la eficacia en la prevención de la gripe, la vacuna reduce las complicaciones graves de la Gripe:

- disminuye $70 \%$ las internaciones por cuadros respiratorios,

- reduce $85 \%$ la mortalidad entre ancianos no institucionalizados y previene el agravamiento de condiciones crónicas (EPOC, insuficiencia cardíaca, etc.).

- En pacientes de $3^{\text {er }}$ nivel la vacuna disminuye

- $50 \%$ las internaciones,

- $60 \%$ el riesgo de neumonía y

- $75-80 \%$ la mortalidad.

En población general, de bajo riesgo disminuyó casi un 30\% la tasa de ausentismo laboraly la incidencia de cuadros respiratorios en general.

La vacuna para gripe y la antineumocóccica pueden darse al mismo tiempo en sitios separados sin aumentar los riesgos de efectos adversos. En niños puede aplicarse junto al esquema de inmunizaciones pero dado que puede provocar fiebre en los muy pequeños sería prudente alejarla de la DPT o bien reemplazar ésta con la DtaP (con pertusis acelular).

\section{Viajeros}

En el hemisferio norte la estación gripal va de noviembre a abril con un pico desde fin de diciembre al inicio de marzo. En áreas templadas de ambos hemisferios puede haber exposición aún en verano, especialmente con la presencia de turistas de diferentes partes del mundo.

Dado el corto período de incubación de la gripe, la enfermedad clínica puede aparecer durante el viaje, lo que puede ser peligroso en pacientes de riesgo. Por estas razones además de la vacunación antigripal actualizada del hemisferio propio debería procurarse la correspondiente al otro hemisferio. La profilaxis con antivirales (amantadina-rimantina) puede ser necesaria durante las 2 semanas siguientes a la vacunación o mientras dure la exposición de no recibir la inmunización apropiada.

\section{Drogas Antivirales}

Aunque la vacunación es el principal método de control de la gripe, los agentes antivirales tienen un rol en la prevención y tratamiento de la gripe por el virus de la influenza tipo A pero son inefectivas contra el tipo B y otros patógenos respiratorios. 
La amantadina y la rimantadina (ambas disponibles en el mercado Argentino) tienen utilidad en la prevención.(70-90\% de eficacia previniendo enfermedades secundarias a la gripe) y tratamiento de la gripe. Cuando se administra dentro de las 48 horas del inicio sintomático, reduce aproximadamente en 24 hs el período febril y malestar sistémico.

Indicaciones: la profilaxis durante el pico de actividad gripal (> costoefectividad que durante toda la estación gripal) es una alternativa en pacientes de alto riesgo con contraindicación a la vacuna, baja probabilidad de adecuada respuesta inmune (inmunodeprimidos) o con vacunas ineficaces por cepa epidémica diferente a la de la vacuna. También en situaciones especiales (epidemias en geriátricos, brotes nosocomiales) aumentando el efecto protector en los pacientes que ya habían sido vacunados, indicándose desde la vacunación durante 2 semanas ( 6 semanas en niños vacunados por 1ra vez). Debería considerarse su uso durante el pico de actividad o durante brotes epidémicos en personal de salud o de instituciones de 3 er nivel no vacunados. Posología: la amantadina se administra en dosis únicas por Vía Oral de $4,4 \mathrm{mg} / \mathrm{Kg} /$ día de 1 a 9 años, de $200 \mathrm{mg} /$ día de 10 a 64 años y 100 $\mathrm{mg} /$ día en > de 65 años (se ajusta según función renal y hepática y en persona con antededentes de convulsiones). La rimantadina en $>$ de 10 años $100 \mathrm{mg}$ ( 1 comprimido) 2 veces por día y en los < de 10 años $5 \mathrm{mg} / \mathrm{kg} /$ día (sin exceder los $150 \mathrm{mg} /$ día).Efectos adversos: 5-33\% cuando se emplea en forma prolongada, incluyendo molestias gastrointestinales, nerviosismo, alucinaciones, convulsiones, aturdimiento, insomnio y pérdida de apetito (también pueden aparecer efectos anticolinérgicos). Los efectos adversos sobre el SNC son menores con rimantadina Precauciones: los efectos sobre el sistema nervioso se exacerban con los anticolinérgicos, antihistamínicos o tiazidas. Contraindicaciones: hipersensibilidad, embarazo y lactancia.

Las personas tratadas por gripe con amantadina o rimantadina pueden llegar a diseminar virus resistentes, especialmente luego de 5-7 días de tratamiento y pueden transmitirlos a los contactos por lo que deberían discontinuarse los antivirales tan pronto exista mejoría clínica (generalmente a los 3-5 días de terapia) o 24-48 Hs luego de la desaparición de la sintomatología.

\section{Nuevos antivirales}

Un nuevo grupo de antivirales son los inhibidores de la neuroaminidasa: el zanamivir y oseltamivir. Son compuestos que especificamente inhiben la acción de la enzima neuroaminidasa, esencial para la replicación viral..Los estudios en curso con drogas antivirales que inhiben las proteínas de superficie de la influenza, como la neuroaminidasa, previniendo de ese modo la replicación viral, se muestran prometedores. Como estas drogas se dirigen al sitio activo de la molecula de neuroaminidasa, son activas frente al virus influenza $A$ y $B$, y es improbable que la variación antigénica del virus afecte su eficacia.

El primero de la inhibidores que se desarrolló fue el zanamivir que demostró disminuir la duración y reducir la severidad de los síntomas comparado con placebo. Este y otros trabajos establecieron el precedente de que la inhibición de la neuroaminidasa del virus de in- fluenza por medio de drogas antivirales selectivas, reduce la replicación viral en los seres humanos y provee un beneficio clínico. Actualmente el zanamivir se administra por vía intranasal, por inhalación de un polvo seco o mediante un nebulizador y no tiene biodisponibilidad oral. También se han reportado estudios, que parecen prometedores, utilizando el zanamivir para la prevención de influenza. El estudio de Monto y col. examina la eficacia del zanamivir administrado una vez al día por un período de 4 semanas. Se estudiaron 1107 pacientes adultos sanos entre 18 y 69 años durante noviembre de 1997, previo al período invernal. Se randomizaron para recibir placebo y $10 \mathrm{mg}$ día de zanamivir administrado por vía nasal. La eficacia reportada fue del $67 \%$ (IC $95 \% 39 \%-83 \%, p<0.001$ ) en prevenir el caso de influenza definido clinicamente ( 3 o más de los siguientes: tos, cefalea, odinofagia, mialgia o temperatura $\geq 37.8^{\circ}$ y confirmado por laboratorio. La eficacia fue del $84.5 \%$ (IC95\% 55\%-94\%, p=0.001) cuando se definió solo fiebre $>$ a $37.8^{\circ}$ y confirmación del virus influenza por laboratorio. Los eventos adversos fueron similares en ambos grupos. Para todos los casos de influenza ocurridos en ese período invernal, con o sin síntomas, la eficacia fue 31\% (IC $95 \% 4 \%-50 \%, p=0.03$ ).

El zanamivir está aprobado por la FDA para el tratamiento de la infección aguda para adultos $\geq 18$ años sintomáticos dentro de los 2 primeros días de la enfermedad. Esta indicación se basa en estudios con casos de influenza $\mathrm{A}$. La dosis recomendada de zanamivir para personas $\geq 12$ años es 2 inhalaciones 2 veces por día por 5 días.

El nuevo objetivo en este grupo de drogas fue disponer de un fármaco que se administrara por vía oral y a través de varias modificaciones químicas se ha incorporado recientemente el oseltamivir. Estudios con voluntarios, oseltamivir vs placebo, han demostrado reducir la duración de la enfermedad en 1 día aproximadamente y severidad de los síntomas ; como así también las complicaciones (sinusitis, neumonia,etc). El efecto adverso más frecuentemente reportado fue nauseas.

El oseltamivir está aprobado para tratamiento de la infección aguda para adultos $\geq 18$ años sintomáticos. No hay datos publicados acerca de la efectividad del oseltamivir en grupos de alto riesgo.

La dosis recomendad para $\geq 18$ años es $75 \mathrm{mg}$ dos veces por día durante 5 días. La reducción de la dosis debe realizarse a personas con clearence de creatinina $<30 \mathrm{~mL} / \mathrm{min}$.

Con los datos actuales podemos decir que los inhibidores de la neuroaminidasa han probado ser útiles en el tratamiento (recomendación del CDC 1/2000) y no está aprobada aún su recomendación en la profilaxis de la influenza. La utilización de estos fármacos está condicionada por los costos y el momento de su indicación, ya que no hay evidencia de eficacia una vez transcurridos los dos primeros días.

Es interesante pensar que si se lograraran reducir los costos, la estrategia más costo efectiva y de mayor impacto poblacional debería considerar la acción complementaria de la vacunación y la medicación antiviral para reducir las complicaciones de la gripe y su mortalidad atribuible; especialmente en los grupos de riesgo.

\section{Referencias}

MMWR, january 2000:49(03)53-57

www.cdc.gov

www.who.int/wer

American College of Physicians. American College of Physicians Task Force on Adults Inmunization, Infectious Diseases Society of America. Guide for Adults Inmunization. 3rd ed. Philadelphia. 1994

U.S. Preventive Services Task Force. Guide to clinical preventive services. Baltimore: Williams \& Wilkins, 1996.

General recommendations on immunization: recommendations of the advisory Commitee on Immunizaton Practices (ACIP). MMWR Morb Mortal Wkly Rep 1994; 43(RR-1):1-38.

Hayden F, Osterhause A, Treanor J y col. Efficacy and safety on the neuraminidase inhibitor zanamivir in the treatment of infleuenza virus infections. $N$ Engl med $1997 ; 337: 874-880$

Hayden F, Treanor J, Betts R y col. Safety and efficacy on the neuraminidase inhibitor Gg167 in experi mental human influenza. JAMA 1996; 275: 295-299 Monto A, Robinson D, Herlocher y col. zanamivir in the prevention of influenza among health adults. JAMA 1999; 275: 31-35

Hayden F, Treanor J, Scott F, et al Use of the oral neuroaminidse inhibitor oseltamivir in experimental human influenza: randomized, controlled trials for prevention and treatment. Preliminary publication 6-10-99 (JAMA Feb 2000) 